\title{
Effects of an occupational safety programme: A comparative study between different training methods involving secondary and vocational school students
}

\author{
Matilde A. Rodrigues*, Claudia Vale, Manuela V. Silva \\ Department of Environmental Health, Research Centre on Environment and Health, School of Health of Polytechnic Institute of Porto, Porto, Portugal
}

\section{ART ICLE INFO}

\section{Keywords:}

Occupational safety

Occupational safety programme

Secondary school

Students

Training methods

Vocational school

\begin{abstract}
A B S T R A C T
Strategies for incorporating proper training in occupational safety at secondary schools are important, since young workers are more likely to be injured at work. However, for a successful educational intervention, an effective Occupational Safety Programme (OSP) with appropriate training methods should be designed and implemented. This study intends to analyze and compare the effects of an OSP in students from diverse school settings, when different training methods are applied. An OSP was designed focusing on the risks related to handling machinery and maintenance tasks and delivered to 301 students from two secondary schools and two vocational schools from the North of Portugal. The sample was divided into three groups, and for each group, a different training method was applied: theory-based; demonstration-based or testimonies-based. To assess its effectiveness, a questionnaire was developed for evaluating the following dimensions: risk acceptance, safety commitment, intended safety behaviors and safety knowledge. The questionnaire was applied two weeks before and after the OSP. A significantly positive effect of the OSP was identified in all dimensions. Comparisons between the three methods showed a greater effect of the testimonies-based intervention in risk acceptance and intended safety behaviors; however, for safety knowledge and safety commitment this was the least effective method. The influence of school type was observed for the safety behaviors and safety commitment dimensions. In conclusion, this study's results suggested that more engaging methods had larger effects on student risk acceptance and intended safety behaviors, while expositive and demonstrative methods were more suitable to improve safety knowledge and commitment
\end{abstract}

\section{Introduction}

Many students wish to enter the job market right after finishing their secondary education. Some of them even accumulate jobs during their studies, working during summer, after school and/or at weekends, to get some income. However, it is broadly acknowledged that young workers (those within the age group of 15-24years; ILO, 2012) are particularly vulnerable to injuries at work (Delp et al., 2002; Schulte et al., 2005; Breslin and Smith, 2005; Lavack et al., 2008). In fact, high rates of injury among this subgroup of workers led some authors to report this phenomenon as a pressing public health issue (see e.g. Schulte et al., 2005; Apostolico and Shendell, 2016).

The main reasons pointed out for the vulnerability of young workers to suffer an occupational accident are their low experience and knowledge on how to deal with the required tasks and the risks they may face (Thamrin et al., 2010; Webster, 2013; Laberge et al., 2016).
Young workers also have traits of immaturity and willingness to face challenges and responsibilities, which might lead them to accept performing tasks for which they are not yet prepared (Lavack et al., 2008; NIOSH, 2015). They are also likely to experience more unsafe working conditions than older workers. They are frequently involved in jobs that require low technical skills, working long and late hours and often without safety training (Zierold and Anderson, 2006; Breslin et al., 2007a). Furthermore, working contracts characterized by part-time and temporary employment are common among young workers (Breslin et al., 2007b), which has been related to poorer safety conditions (Quinlan et al., 2001; Aronsson et al., 2002; Breslin and Smith, 2005).

Vocational school students are also an interest group in what regards to this matter. Vocational programmes are intended to provide individuals with the necessary knowledge and skills for different careers they may wish to pursue, involving industry in education and linking curricula to the needs of the labour market (Schulte et al., 2005; OECD, 2014). These programmes include training hours in a

\footnotetext{
* Corresponding author at: Rua Valente Perfeito, no 322, 4400-330 Vila Nova de Gaia, Portugal.

Email address: mar@estsp.ipp.pt (M.A. Rodrigues)
} 
working context, where students begin their apprenticeship. During the training period, students can be exposed to the same occupational risks as workers. Raykov and Taylor (2013) found a high incidence of injuries among youth who had participated in high school apprenticeship programmes in Canada.

Against this background, it has been widely recognized that trainees and young workers should attend a proper safety training programme before being integrated in a working context and while working on site (Goldenhar et al., 2001; Pisaniello et al., 2013; NIOSH, 2015). However, because several companies do not provide appropriate training programmes to newly-hired employees and apprentices (Goldenhar et al., 2001; Runyan et al., 2007; Smith and Mustard, 2007; Thamrin et al., 2010), the role of schools in endowing youths with the fundamental knowledge and skills for a safe work becomes particularly important (Schulte et al., 2005; Thamrin et al., 2010; Pisaniello et al., 2013). According to Schulte et al. (2005), what students can learn during this kind of programmes sets the foundation that may affect their work experiences for many years. Thamrin et al. (2010) and Pisaniello et al. (2013) went even further, asserting that, by making its attendance compulsory in secondary education, it would be possible to ensure that all young workers receive a minimum level of education on safety. In Portugal, efforts to incorporate Occupational Safety \& Health (OSH) topics in secondary and vocational school curricula are ongoing (see for further information the National Strategy for Safety and Health at Work 2015-2020, Resolution of the Ministries Council n ${ }^{\circ}$ 77/2015).

A school-based Occupational Safety Programme (OSP) is a primary intervention strategy to prevent injuries among young workers. Its purpose is to empower students with the necessary knowledge and skills to deal with the hazards that they may face in the future at their workplace. It must address concepts and issues about workplace risks, workers' protection and exposure control, as well as workers' rights and duties (Balanay et al., 2014). However, to an OSP be effective, appropriate training methods should be applied. The literature describes some methods to be applied in training programmes aimed at the prevention of work accidents and diseases (see e.g. Burke et al., 2006; Lavack et al., 2008; Twisk et al., 2014; Liao, 2014); but still, there appears to be limited evidence about their effectiveness. While previous research in this field indicated its positive effect on safety indicators (see e.g. Linker et al., 2005; Liao, 2014), there is still no consensus about the real impact of an OSP or the factors that enhance its effectiveness. Furthermore, previous studies did not consider some important indicators related to safe behaviors, such as safety commitment and risk acceptance (Rodrigues et al., 2015a,b).

The main objective of this study was to compare three training methods applied to an OSP in school settings, analyzing their effects on students' risk acceptance level, safety commitment, intended safety behaviors and safety knowledge. Considering that vocational-school students may have unique characteristics and study conditions when compared to other students, the following hypotheses were defined:

H1. The OSP has a positive effect on the levels of knowledge, intended safety behaviors, safety commitment and risk acceptance.

H2. Different training methods have different effects on safety knowledge, intended safety behaviors, safety commitment and risk acceptance.

H3. There are significant differences between the effects of safety interventions in secondary schools and in vocational schools.

\section{Methodology}

\subsection{Sample}

Data collection involved four upper-secondary schools from the Porto Metropolitan Area, of which two were common secondary schools and two were vocational schools. A total of 301 students were involved in this study: $47.5 \%$ were students from scientific-humanistic courses (secondary schools) and $52.5 \%$ from vocational courses (vocational schools).

All the subjects were recruited by their school teachers, considering the existing classes and their readiness to take part in the study. Most of the students were males (65.2\%) and aged on average 17.4 years $(\mathrm{SD}=1.3)$.

\subsection{Study design}

An OSP was designed based on previous guidelines and delivered to the students using three different training methods: theory-based, demonstration-based, and testimonies-based.

In this study, a quasi-experimental design was used, which involved a comparison between pre- and post-test scores. The independent variables were training methods and school type, and the dependent variables were risk acceptance, safety commitment, intended safety behaviors and safety knowledge. The study design included quantitative data obtained from questionnaires, which assessed the short-term effect of each independent variable on each dependent variable under analysis. The same questionnaire was applied to collect data and to test the effectiveness of each intervention method two weeks before and after delivering the OSP. The period between the intervention and the post-assessment was limited to the time available for this study. However, to assess a short-term effect, this timespan was considered sufficient. This procedure was previously adopted by Liao (2014). Furthermore, it was not the aim of this study to assess the effect of an OSP on behavioral changes, but only on the students' intentions to adopt some safe behaviors. Unlike knowledge, behavior changes need a larger period between pre- and post-test to be assessed (Burke et al., 2006).

The study was performed in accordance with the ethical standards set in the 1991 declaration of Helsinki. All the participants received detailed information prior to the study and, when applicable, parental authorizations were requested.

\subsection{Training sessions}

\subsubsection{Occupational safety programme}

The topics covered in the OSP were chosen based on the "Youth@Work: Talking Safety" (NIOSH, 2015) and on the "Worker's Health and Safety Awareness in 4 Steps" (Ontario Ministry of Labour, 2012) curricula. Technical bibliography, particularly handbooks, were also used as a support to the OSP contents (e.g. Harms-Ringdahl, 2001). All the contents were focused on the main hazards and the corresponding risks related to handling machinery and performing maintenance tasks in industrial settings, since most of the vocational students involved in this study were in courses related to this field, and the number and severity of accidents related to these tasks remains high (Eurostat, 2009).

The contents that constituted the OSP were organized into four parts. The first part included a brief introduction to industrial accidents and injuries among young workers. Statistics about occupational accidents were presented, and explanations about why young workers are more likely to be hurt on the job were provided. Fundamental concepts on occupational safety were also clarified. In the second part, duties of employers and workers, as well as workers' rights were presented, considering the current legal framework. Subsequently, in the third part, common hazards and the corresponding risks to the safety of workers were addressed. Risk control measures were also explained. The topics for analysis were: mechanical risk, chemical risk and other specific risks, such as electrical risk and explosive atmospheres. Risks related to physical agents, such as noise and vibrations, were also covered, because some schools mentioned them as being important and fitting the 
theme. In the last part, issues linked to worker involvement in the improvement of occupational safety were addressed.

A pilot version of the OSP was tested in a group of 10 students, which helped to understand if the contents were suitable for the time available for the sessions and if they were easily understandable.

\subsubsection{Training methods and procedures}

The contents composing the OSP were taught through three training methods, which differed in relation to the level of engagement. Each student was subject to a session where a single method of knowledge transfer was applied. The first one was called "theory-based". This is an expository training method with a low engagement level. In this intervention, the theoretical contents were presented in a power-point format, and the information was transmitted using formal exposure. In the "demonstration-based" intervention, the presentation of the different hazards, as well as the explanations about risks, control measures and the other contents included in the OSP, were based on discussions supported by realistic photographs and videos taken in five companies from different sectors of activity (furniture, metallomechanics and automotive). Videos from machine manufacturers were also used to complement the examples of control measures and good practices. The last training method was called "testimonies-based", since testimonies of workers who had suffered an accident while handling a machine or while performing maintenance tasks were used to support discussions and explanations about the different OSP contents. The testimonies were collected in the same five companies, and in all of them the workers explained the causes of the accident, their consequences and corresponding measures which could have been taken to avoid the accident. In the interventions where demonstration and testimonies-based methods were applied, the research team promoted dialogue and reflection through analyses and guided discussions within the groups of the presented cases.

The research team delivered the OSP in a 90- min session, with time for discussion, and took measures to keep the homogeneity among all groups of participants. Three groups of students from the same year were defined in each school in order to avoid limitations related to age difference, background diversity and communication.

\subsection{Questionnaire design}

The researchers developed a self-report questionnaire called "Safety Inquiry for Young Workers" (SIYW) and administered it to the study sample. The questionnaire was developed following a four-stage process: (1) designing of a preliminary version, (2) testing of the preliminary version, (3) incorporation of the comments and suggested improvements, and (4) development of a final version.

The questionnaire had two main parts. The first part comprised general questions for characterizing the students, such as age, gender, if they knew someone who had suffered a serious occupational accident, as well as if they had any previous training on safety and for how many hours. The second part included items oriented to assess four specific dimensions: (1) risk acceptance, (2) safety commitment (3) intended safety behaviors and (4) safety knowledge.

The first version of the questionnaire was handed to 10 students of the first year of college, with ages close to the ones of the secondary school, who had limited knowledge on safety matters, and also to 6 senior undergraduate students with technical knowledge on OSH. They were requested to review, examine and test it. Furthermore, the questionnaire was applied before and after a trial session, in order to assess the suitability of the scales and items included in the four dimensions under analysis. Some improvements regarding the language and the items used were suggested and considered in the final version. Some items were simplified and the language adjusted, while some items were eliminated, since they did not contribute to assess the effect of the OSP.

To analyze the risk acceptance level of the students, six risk scenarios were presented at the beginning; however, an item was eliminated during the validation process, thus achieving a 5-item solution. Students were asked if they would be willing to accept working under the specified conditions in order to keep their jobs. A 5-point Likert scale was used ( $1=$ Never; $5=$ Always). A question with five items was included to analyze the students' safety commitment. They were asked to assess the level of agreement towards each statement, also by using a 5-point Likert scale ( $1=$ Totally disagree; $5=$ Totally agree). Intended safety behaviors were analyzed in the original questionnaire through 11 items; however, three of those items were removed during the validation process. Students were requested to identify possible behaviors that they could see themselves adopting as newly-hired workers, in order to make a good impression or to avoid a bad impression (5-point Likert scale; 1 = Definitely not; 5 = Definitely yes). The knowledge of students on safety matters was assessed through a 10-item measure. They were requested to choose one option out of three possibilities: "True", "False" and "I don't know". A description of the items considered in the final version for each dimension is presented in Table 1.

\subsection{Data analysis}

To verify the underlying factor structure of the questionnaire, an exploratory factor analysis using orthogonal Varimax rotation was performed on the items where the Likert scale was used. This analysis helps to identify the interdependence of the items, reducing them to a smaller set of factors (or dimensions). Items 2.2, 3.1, 3.2 and 3.5 were rephrased and presented with the same intention (negative or positive) of the remaining items of the dimension for analysis. The Kaiser-Meyer-Olkin Measure of Sampling Adequacy (KMO) and the Bartlett's Test of Sphericity were firstly applied to assess the quality of the correlations between the items for the factor analysis. The KMO index ranges from 0 to 1 and should be higher than 0.5, while the Bartlett's Test of Sphericity should result in a significant $p$-value ( $p$-value $<0.05$ ) (Field, 2009). For the factors identification, the Kaiser's criterion was used (eigenvalues $>1$ ), as well as a scree plot analysis. Only items with loadings higher than 0.4 were grouped and judged on their applicability to an underlying concept. Extracted items comprising a construct were examined by Cronbach's alpha for internal consistency.

Basic descriptive statistics were calculated for all variables. The results of the 10-item knowledge measure were summarized according to the percentage of correct answers. Mean ratings were calculated for each item of the other dimensions.

Group differences were analyzed. The participants could not be linked successfully due to anonymity requirements, so the data were treated as independent for statistical analysis. T-tests were used to compare differences in continuous variables, and chi-square tests were used to assess differences in categorized variables. For ordinal variables, non-parametric tests were applied. The Mann-Whitney $U$ test was used to compare the rankings of each item before and after safety interventions, and the Kruskal-Wallis test was used to compare differences between the three types of interventions.

The total scores were determined considering the obtained loadings for each item and used in subsequent analyses. A two-way analysis of variance (ANOVA) was used to test differences in total factor scores for the different intervention methods and school types and to quantify any interaction between factors. Tukey's post hoc tests were carried out for pairwise comparisons whenever the ANOVA analysis revealed significant differences. 
Table 1

Description of the items that were a part of the four dimensions to assess the effectiveness of the OSP.

Dimension

1. Risk Acceptance $(1=$ Never; $5=$ Always $)$

1.1. Not complying with some safety rules to increase my productivity and to make a good impression on my supervisors

1.2. Accepting small risks that can result in small cuts while performing my tasks

1.3. Performing tasks for which I do not have the required training/knowledge

1.4. Performing tasks without the use of the necessary PPE, if these are not made available

1.5. Working with machines without all the necessary protections to increase the company's productivity

2. Safety commitment ( 1 = Strongly disagree; $5=$ Strongly agree)

2.1. Whenever I have a question, I should raise it to my supervisor, even if it makes me look ignorant

2.2. Safety should be my priority while I am doing my job, not productivity

2.3. I must report unsafe situations to my supervisors whenever I detect them

2.4. Safety rules should not be disregarded, even at the end of the work-shift when I

just want to go home

2.5. I must warn my colleagues whenever I see them infringing a rule or a safety procedure

3. Intended Safety Behaviors ( $1=$ Absolutely not; $5=$ Definitely yes $)$

3.1. I will not try to work faster in order to make a good impression on my supervisor

3.2. If I see a colleague getting a shock, I will not try to grab him and pull him off of the site

3.3. In tasks where I ought to use several materials and equipment, I will try to avoid accumulating them in my workplace

3.4. I will use PPE during my working schedule, even if it causes discomfort

3.5. I will not use my mobile phone in risky areas, not even in emergency situations

3.6. I will turn off the machine and lock out the plug before doing its maintenance,

so as to prevent anyone from turning it on

3.7. I will check if the machines can be operated in places with an explosive atmosphere whenever this situation arises

3.8. If a piece of wood gets stuck in the cutting area of the machine, I will first stop the machine and only then remove the waste using my hands

4. Knowledge (\% of correct answers)

4.1. It is easy to identify electrical risk factors, because the electrical current is perceptible to our senses

4.2. Tetanisation is a sustained muscle contraction stimulated by electricity, where the victim cannot let go off the source of electricity

4.3. A worker who performs maintenance tasks on an electrical panel should wear safety gloves and a face mask

4.4. When handling dangerous chemicals, workers must use a respirator, work gloves, safety goggles and safety clothing

4.5. Safety data sheets must be present in all workplaces where chemicals are handled

4.6. Wood dust can be explosive in certain situations

4.7. Only a designated worker can use fire extinguishers

4.8. Cell phones can be an ignition source for an explosion, if used in an explosive atmosphere

4.9. Any worker can perform maintenance of working equipment, as long as they are turned off

4.10. An explosion can result in flames, pressure bursts, toxic combustion products and reduced oxygen concentration

Table 2

General characteristics of participants before and after the OSP, by school type.
The significance level was considered as $\alpha=5 \%$. Data analysis procedures were performed using the statistical software Statistical Package for Social Sciences (IBM SPSS® version 20, Inc., Chicago, Ill).

\section{Results}

\subsection{Study subjects}

On total, of the 301 students involved, 142 students of secondary schools and 157 of vocational schools completed the questionnaires handed to them before and after the OSP, with the researchers ensuring that the subjects in both moments were the same (Table 2). As shown in Table 2, the two groups of students under analysis were different concerning gender and age $(\mathrm{p}<0.001)$. Almost all vocational students were males and their mean age was about 18 years old. On the other hand, the majority of secondary school students included in the study were females and their mean age was about 17 years old. Results between both groups were also significantly different in relation to previous occupational safety training $(\mathrm{p}<0.001)$. In regard to vocational schools, $40.8 \%$ of subjects reported to have received previous training on safety matters. On the other hand, the percentage of secondary school students subjected to this kind of training was lower (4.2\%).

Despite the differences between secondary school and vocational school students, the data showed that there were no significant variances in the distribution of the sample within the same groups before and after the OSP ( $p>0.05)$.

\subsection{Factor analysis}

The overall sampling was deemed to be appropriate for the factor analysis, as indicated by the KMO value of 0.943 . Data matrix had also sufficient correlation to factor analysis, since the Bartlett's Test of Sphericity was also significant $\left(\chi^{2}=4473.118, \mathrm{p}<0.001\right)$.

In the first analysis, four items had communality values lower than 0.4 and were removed from further analysis, because there was no sufficient common variance among them (Turnberg and Daniell, 2008). Through subsequent analysis of the remaining 18 items, three factors emerged, accounting for $55.6 \%$ of the variance. Results from EFA reflect a scale composition in accordance with the starting assumptions, confirming the unidimensionality of the following factors: risk acceptance, safety commitment and intended safety behaviors. Loadings were adequate for all items, since they were higher than 0.4 (Hair et al., 1995). The internal consistency for individual factors was tested separately. Cronbach's alpha was $>0.70$ for all dimensions, which is considered satisfactory for basic research (Nunnally et al., 1994).

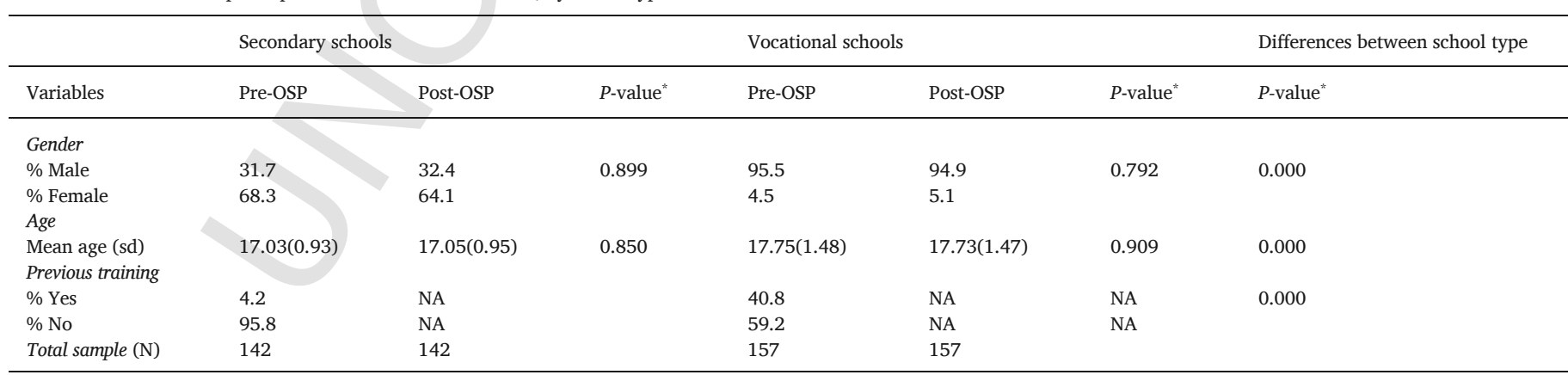

* Chi square tests were used for categorical variables and t-tests were used for continuous variables to determine statistically significant differences; NA - Not Analyzed. 


\subsection{Effectiveness of the intervention methods}

The effectiveness of training methods was evaluated comparing the mean scores of each item before and after the sessions, being the results presented in Tables 3-6.

Table 3 shows the results for the risk acceptance scenarios under analysis, by training method. While before the OSP most of the students were willing to accept most of the risk scenarios rarely and a few of them sometimes, after the training sessions their level of risk acceptance had decreased, and on average, they were willing to never accept most of the scenarios presented. In fact, statistically significant changes between both moments were found for all the three training methods and for all the scenarios $(\mathrm{p}<0.001)$, despite results denoting higher changes, on average, in the risk acceptance at the end of the OSP for the group submitted to the testimonies-based method.

Table 4 shows the results for safety commitment. The groups submitted to the theoretical-based and demonstration-based methods 'agreed' with the presented scenarios before the OSP, showing already a tendency for safety commitment. However, the group submitted to the testimonies-based intervention method had a lower level of agreement. After the OSP, the safety commitment level was significantly higher than before $(\mathrm{p}<0.001)$; in general, they strongly agree with the presented scenarios, regardless of the training method to which they were submitted.

Results for the intended safety behaviors before and after the OSP are shown in Table 5; 1 represents a tendency for unsafe behaviors and 5 for safe behaviors. Students reported the intention to adopt some unsafe behaviors before the OSP, while they saw as probable the intention to adopt a safe behavior after the OSP, mainly the ones submitted to the testimonies-based method. However, significant differences between both moments were found for all training methods $(\mathrm{p}<0.001)$.

Table 6 presents the responses to the 10 -items about safety knowledge. Results before delivering the OSP indicate that most students were aware of the need to use personal protective equipment (PPE) when handling dangerous chemicals. Furthermore, over a half knew about the need to use PPE during electrical maintenance tasks, the consequences of explosions and ignition sources, the need of an easier access to safety data sheets and the necessary qualifications of the maintenance technician. However, in general, they had limited knowledge related to electricity. They did not know how difficult it is to identify electrified metal because electricity is invisible, or even the consequences of an electrical accident. They also did not know that wood dust can trigger explosive atmospheres under certain conditions, or who can use a fire extinguisher. After the OSP, the percentage of correct answers was significantly higher than the previous one $(\mathrm{p}<0.05)$, with the exception of the item 4.4. In the group submitted to the theoretical-based method, where the percentage of correct answers was high in both moments, as well as for the item 4.9, where the percentage of correct responses was similar in both moments.

\subsection{Comparisons of the OSP effect by intervention method and school type}

In a first stage, differences before the OSP in relation to school type were analyzed. Data showed significant differences between schools for all dimensions, i.e., risk acceptance, safety commitment, intended safety behavior and knowledge $(\mathrm{p}<0.001)$. An analysis of the mean rankings showed better results, in general, for secondary school students (mean difference: Risk acceptance $=2.08$; Safety commitment $=-1.05$; Safety behaviors $=-1.06$ ), with the exception of safety knowledge, for which better results were found among vocational school students (mean difference: safety knowledge $=2.24$ ).
A two-way ANOVA was carried out to assess the effect of the training methods and the school type on each dimension after the OSP. For risk acceptance, a significant effect was found only for training methods $(p<0.05)$ and no interaction effect was observed $(p>0.05)$. The Tukey HSD Post Hoc analysis showed that a testimonies-based training approach had a stronger effect on risk acceptance than a theoretical-based approach $(\mathrm{p}<0.05)$. In regard to safety commitment and intended safety behaviors, there were significant effects for training methods $(\mathrm{p}<0.01)$ and school type $(\mathrm{p}<0.05)$ as well as a significant interaction between them $(\mathrm{p}<0.01)$. Tukey HSD Post Hoc analysis showed that a testimonies-based training method has a stronger effect on intended safety behaviors than the demonstration-based or theoretical-based methods ( $\mathrm{p}<0.05$ ); however, a smaller effect for the testimonies-based method against the other two was identified for safety commitment $(\mathrm{p}<0.05)$. Additionally, Fig. 1 shows higher scores of intended safety behaviors and safety commitment in the groups submitted to the theoretical-based and demonstration-based training methods in secondary schools, but a higher effect of the testimonies-based training method in vocational schools. For knowledge, a significant effect was found for training method $(\mathrm{p}<0.05)$ and an interaction effect between training method and school type was observed $(p<0.05)$. The Tukey HSD Post Hoc analysis revealed that a testimonies-based training method has a lower effect on safety knowledge than the demonstration-based or theoretical-based methods $(\mathrm{p}<0.05)$.

\section{Discussion}

Despite the importance of a school-based OSH education, results suggest that several schools do not offer safety training/awareness in their curricula, or at least not to all students. This was particularly evident in secondary schools, where only a paltry percentage of students reported having received previous training in OSH-related topics. These results were already expected, since the focus of these schools is on students' entrance into university, and strategies for implementing these contents in the secondary school system are still taking shape. Similar evidence was previously observed by Pisaniello et al. (2013). However, it is important to note that some students can drop out of school at this stage or accumulate a job during the university period, being therefore essential to make these issues a part of secondary school curricula (Schulte et al., 2005; Thamrin et al., 2010; Pisaniello et al., 2013). By making the attendance of these subjects/programmes compulsory, it would be possible to reach all students (Thamrin et al., 2010; Pisaniello et al., 2013). In relation to the vocational school results, it is worrying that only about $41 \%$ of students had received previous training in occupational safety. The vocational students included in this study were in the last year of their programme, and some on-site training could already have occurred. Overall, the results found in this study about training in schools were worse than the ones achieved by Thamrin et al. (2010) with first year college students, where about $40 \%$ of the local students had not received training. However, in this study, the pre-OSP questionnaires were applied at the end of the second trimester, and some students could still expect to have this kind of training in the last trimester (the third one).

Regarding the pre-OSP moment, results showed that students would rarely accept most of the risk scenarios, which is good. However, they were willing to accept some of them sometimes, such as "Performing tasks for which I do not have the required training/knowledge." Students were also willing to adopt some unsafe behaviors, such as working faster to make a good impression on their supervisor or accumulate materials and equipment in the workplace. Raykov and Taylor (2013), in a study with young apprentices, had already observed that youths are eager to please. The findings of Breslin et al. (2007b) on young workers can also help to understand these results. In a context where 
Table 3

Risk acceptance level before and after the OSP, by training method.

\begin{tabular}{|c|c|c|c|c|c|c|c|c|c|c|c|c|}
\hline \multirow[t]{2}{*}{ Item } & \multicolumn{4}{|c|}{ Theoretical-based } & \multicolumn{4}{|c|}{ Demonstration-based } & \multicolumn{4}{|c|}{ Testimonies-based } \\
\hline & $\mathrm{Q} 1(\mathrm{x} \pm \mathrm{sd})$ & $\mathrm{Q} 2(\mathrm{x} \pm \mathrm{sd})$ & Q2-Q1 & $P$-value & $\mathrm{Q} 1(\mathrm{x} \pm \mathrm{sd})$ & $\mathrm{Q} 2(\mathrm{x} \pm \mathrm{sd})$ & Q2-Q1 & $P$-value & $\mathrm{Q} 1(\mathrm{x} \pm \mathrm{sd})$ & $\mathrm{Q} 2(\mathrm{x} \pm \mathrm{sd})$ & Q2-Q1 & $P$-value \\
\hline 1.1 & $2.02(0.95)$ & $1.57(0.84)$ & -0.45 & 0.000 & $2.31(1.00)$ & $1.36(0.73)$ & -0.95 & 0.000 & $2.67(0.99)$ & $1.19(0.44)$ & -1.48 & 0.000 \\
\hline 1.2 & $1.93(1.08)$ & $1.48(0.79)$ & -0.45 & 0.002 & $2.26(1.10)$ & $1.27(0.69)$ & -0.99 & 0.000 & $2.62(0.95)$ & $1.26(0.58)$ & -1.36 & 0.000 \\
\hline 1.3 & $2.21(0.91)$ & $1.46(0.70)$ & -0.75 & 0.000 & $2.46(1.24)$ & $1.59(0.79)$ & -0.87 & 0.000 & $3.11(0.16)$ & $1.47(0.74)$ & -1.64 & 0.000 \\
\hline 1.4 & $1.80(0.95)$ & $1.41(0.74)$ & -0.39 & 0.003 & $2.17(1.13)$ & $1.24(0.58)$ & -0.93 & 0.000 & $2.73(1.00)$ & $1.19(0.59)$ & -1.54 & 0.000 \\
\hline 1.5 & $1.88(1.03)$ & $1.30(0.62)$ & -0.58 & 0.000 & $2.17(1.26)$ & $1.24(0.65)$ & -0.93 & 0.000 & $2.54(0.93)$ & $1.21(0.51)$ & -1.33 & 0.000 \\
\hline
\end{tabular}

$\mathrm{Q}_{1}=$ Before the questionnaire; $\mathrm{Q}_{2}=$ After the questionnaire. 
Table 4

Safety commitment level before and after the OSP, by training method.

\begin{tabular}{|c|c|c|c|c|c|c|c|c|c|c|c|c|}
\hline \multirow[t]{2}{*}{ Item } & \multicolumn{4}{|c|}{ Theoretical-based } & \multicolumn{4}{|c|}{ Demonstration-based } & \multicolumn{4}{|c|}{ Testimonies-based } \\
\hline & $\begin{array}{l}\mathrm{Q} 1 \\
(\mathrm{x} \pm \mathrm{sd})\end{array}$ & $\begin{array}{l}\mathrm{Q} 2 \\
(\mathrm{x} \pm \mathrm{sd})\end{array}$ & Q2-Q1 & $\begin{array}{l}P \text { - } \\
\text { value }\end{array}$ & $\begin{array}{l}\text { Q1 } \\
(x \pm s d)\end{array}$ & $\begin{array}{l}\text { Q2 } \\
(x \pm s d)\end{array}$ & Q2-Q1 & $\begin{array}{l}P \text { - } \\
\text { value }\end{array}$ & $\begin{array}{l}\text { Q1 } \\
(x \pm s d)\end{array}$ & $\begin{array}{l}\text { Q2 } \\
(\mathrm{x} \pm \mathrm{sd})\end{array}$ & Q2-Q1 & $\begin{array}{l}P- \\
\text { val }\end{array}$ \\
\hline 2.1 & $\begin{array}{l}3.85 \\
(0.96)\end{array}$ & $\begin{array}{l}4.55 \\
(0.73)\end{array}$ & 0.70 & 0.000 & $\begin{array}{l}4.01 \\
(0.89)\end{array}$ & $\begin{array}{l}4.55 \\
(0.82)\end{array}$ & 0.54 & 0.000 & $\begin{array}{l}3.18 \\
(0.88)\end{array}$ & $\begin{array}{l}4.63 \\
(0.59)\end{array}$ & 1.45 & 0.0 \\
\hline 2.2 & $\begin{array}{l}4.11 \\
(0.88)\end{array}$ & $\begin{array}{l}4.47 \\
(0.73)\end{array}$ & 0.36 & 0.002 & $\begin{array}{l}4.00 \\
(0.96)\end{array}$ & $\begin{array}{l}4.36 \\
(1.05)\end{array}$ & 0.36 & 0.000 & $\begin{array}{l}3.42 \\
(0.90)\end{array}$ & $\begin{array}{l}4.48 \\
(0.77)\end{array}$ & 1.06 & 0.0 \\
\hline 2.3 & $\begin{array}{l}3.96 \\
(0.96)\end{array}$ & $\begin{array}{l}4.51 \\
(0.75)\end{array}$ & 0.55 & 0.000 & $\begin{array}{l}4.06 \\
(0.91)\end{array}$ & $\begin{array}{l}4.40 \\
(0.97)\end{array}$ & 0.34 & 0.001 & $\begin{array}{l}3.14 \\
(0.95)\end{array}$ & $\begin{array}{l}4.63 \\
(0.67)\end{array}$ & 1.49 & 0.0 \\
\hline 2.4 & $\begin{array}{l}3.74 \\
(1.30)\end{array}$ & $\begin{array}{l}4.50 \\
(0.78)\end{array}$ & 0.76 & 0.000 & $\begin{array}{l}4.01 \\
(1.10)\end{array}$ & $\begin{array}{l}4.58 \\
(0.82)\end{array}$ & 0.57 & 0.000 & $\begin{array}{l}3.18 \\
(1.00)\end{array}$ & $\begin{array}{l}4.57 \\
(0.69)\end{array}$ & 1.39 & 0.0 \\
\hline 2.5 & $\begin{array}{l}3.76 \\
(1.01)\end{array}$ & $\begin{array}{l}4.49 \\
(0.76)\end{array}$ & 0.73 & 0.000 & $\begin{array}{l}3.88 \\
(0.86)\end{array}$ & $\begin{array}{l}4.60 \\
(0.57)\end{array}$ & 0.72 & 0.000 & $\begin{array}{l}3.03 \\
(0.93)\end{array}$ & $\begin{array}{l}4.64 \\
(0.60)\end{array}$ & 1.61 & 0.0 \\
\hline
\end{tabular}

$\mathrm{Q}_{1}=$ Before the questionnaire; $\mathrm{Q}_{2}=$ After the questionnaire.

Table 5

Intended safety behaviors before and after the OSP, by training method.

\begin{tabular}{|c|c|c|c|c|c|c|c|c|c|c|c|c|}
\hline \multirow[t]{2}{*}{ Item } & \multicolumn{4}{|c|}{ Theoretical-based } & \multicolumn{4}{|c|}{ Demonstration-based } & \multicolumn{4}{|c|}{ Testimonies-based } \\
\hline & $\begin{array}{l}\text { Q1 } \\
(\mathrm{x} \pm \mathrm{sd})\end{array}$ & $\begin{array}{l}\text { Q2 } \\
(\mathrm{x} \pm \mathrm{sd})\end{array}$ & Q2-Q1 & $\begin{array}{l}P \text { - } \\
\text { value }\end{array}$ & $\begin{array}{l}\text { Q1 } \\
(\mathrm{x} \pm \mathrm{sd})\end{array}$ & $\begin{array}{l}\mathrm{Q} 2 \\
(\mathrm{x} \pm \mathrm{sd})\end{array}$ & Q2-Q1 & $\begin{array}{l}P \text { - } \\
\text { value }\end{array}$ & $\begin{array}{l}\mathrm{Q} 1 \\
(\mathrm{x} \pm \mathrm{sd})\end{array}$ & $\begin{array}{l}\mathrm{Q} 2 \\
(\mathrm{x} \pm \mathrm{sd})\end{array}$ & Q2-Q1 & $\begin{array}{l}P- \\
\text { val }\end{array}$ \\
\hline 3.1 & $\begin{array}{l}1.82 \\
(1.03)\end{array}$ & $\begin{array}{l}4.07 \\
(0.94)\end{array}$ & 2.25 & 0.000 & $\begin{array}{l}1.73 \\
(1.05)\end{array}$ & $\begin{array}{l}4.26 \\
(0.73)\end{array}$ & 2.53 & 0.000 & $\begin{array}{l}1.71 \\
(0.86)\end{array}$ & $\begin{array}{l}4.18 \\
(1.08)\end{array}$ & 2.47 & 0.0 \\
\hline 3.2 & $\begin{array}{l}2.93 \\
(1.53)\end{array}$ & $\begin{array}{l}4.23 \\
(1.21)\end{array}$ & 1.30 & 0.000 & $\begin{array}{l}3.23 \\
(1.55)\end{array}$ & $\begin{array}{l}4.66 \\
(0.74)\end{array}$ & 1.43 & 0.000 & $\begin{array}{l}2.27 \\
(1.19)\end{array}$ & $\begin{array}{l}4.63 \\
(0.89)\end{array}$ & 2.36 & 0.0 \\
\hline 3.3 & $\begin{array}{l}2.16 \\
(1.11)\end{array}$ & $\begin{array}{l}3.20 \\
(1.31)\end{array}$ & 1.04 & 0.000 & $\begin{array}{l}2.09 \\
(0.86)\end{array}$ & $\begin{array}{l}3.71 \\
(1.27)\end{array}$ & 1.62 & 0.000 & $\begin{array}{l}1.76 \\
(0.74)\end{array}$ & $\begin{array}{l}4.03 \\
(1.00)\end{array}$ & 2.27 & 0.0 \\
\hline 3.4 & $\begin{array}{l}3.15 \\
(1.22)\end{array}$ & $\begin{array}{l}4.07 \\
(1.20)\end{array}$ & 0.92 & 0.000 & $\begin{array}{l}3.40 \\
(1.13)\end{array}$ & $\begin{array}{l}3.86 \\
(1.18)\end{array}$ & 0.46 & 0.003 & $\begin{array}{l}2.69 \\
(1.01)\end{array}$ & $\begin{array}{l}4.47 \\
(0.81)\end{array}$ & 1.78 & 0.0 \\
\hline 3.5 & $\begin{array}{l}3.17 \\
(1.34)\end{array}$ & $\begin{array}{l}3.98 \\
(1.30)\end{array}$ & 0.81 & 0.000 & $\begin{array}{l}2.93 \\
(1.37)\end{array}$ & $\begin{array}{l}4.25 \\
(1.06)\end{array}$ & 1.32 & 0.000 & $\begin{array}{l}2.34 \\
(1.06)\end{array}$ & $\begin{array}{l}4.74 \\
(0.55)\end{array}$ & 2.40 & 0.0 \\
\hline 3.6 & $\begin{array}{l}3.28 \\
(1.25)\end{array}$ & $\begin{array}{l}4.21 \\
(1.24)\end{array}$ & 0.93 & 0.000 & $\begin{array}{l}3.68 \\
(1.14)\end{array}$ & $\begin{array}{l}4.43 \\
(1.07)\end{array}$ & 0.75 & 0.000 & $\begin{array}{l}2.76 \\
(0.99)\end{array}$ & $\begin{array}{l}4.74 \\
(0.50)\end{array}$ & 1.98 & 0.0 \\
\hline 3.7 & $\begin{array}{l}3.12 \\
(1.16)\end{array}$ & $\begin{array}{l}3.83 \\
(1.28)\end{array}$ & 0.71 & 0.000 & $\begin{array}{l}3.15 \\
(1.17)\end{array}$ & $\begin{array}{l}3.91 \\
(1.00)\end{array}$ & 0.76 & 0.000 & $\begin{array}{l}2.60 \\
(1.05)\end{array}$ & $\begin{array}{l}4.62 \\
(0.74)\end{array}$ & 2.02 & 0.0 \\
\hline 3.8 & $\begin{array}{l}2.86 \\
(1.26)\end{array}$ & $\begin{array}{l}3.62 \\
(1.32)\end{array}$ & 0.76 & 0.000 & $\begin{array}{l}3.01 \\
(1.31)\end{array}$ & $\begin{array}{l}3.43 \\
(1.42)\end{array}$ & 0.42 & 0.023 & $\begin{array}{l}2.65 \\
(0.99)\end{array}$ & $\begin{array}{l}4.25 \\
(1.08)\end{array}$ & 1.60 & 0.0 \\
\hline
\end{tabular}

$\mathrm{Q}_{1}=$ Before the questionnaire; $\mathrm{Q}_{2}=$ After the questionnaire.

Table 6

Safety knowledge measured by the percentage of correct responses before and after the OSP, by training method.

\begin{tabular}{|c|c|c|c|c|c|c|c|c|c|}
\hline \multirow[t]{2}{*}{ Item } & \multicolumn{3}{|c|}{ Theoretical-based } & \multicolumn{3}{|c|}{ Demonstration-based } & \multicolumn{3}{|c|}{ Testimonies-based } \\
\hline & Q1\% & $\mathrm{Q} 2 \%$ & $P$-value & Q1\% & Q2\% & $P$-value & Q1\% & $\mathrm{Q} 2 \%$ & $P$-value \\
\hline 4.1 & 18.5 & 63.0 & 0.001 & 28.4 & 77.9 & 0.000 & 17.9 & 78.6 & 0.000 \\
\hline 4.2 & 14.1 & 85.9 & 0.000 & 13.7 & 95.8 & 0.000 & 8.0 & 93.8 & 0.000 \\
\hline 4.3 & 68.5 & 92.4 & 0.000 & 67.4 & 98.9 & 0.000 & 53.6 & 92.0 & 0.000 \\
\hline 4.4 & 91.3 & 96.7 & 0.121 & 90.5 & 100 & 0.002 & 83.0 & 98.2 & 0.000 \\
\hline 4.5 & 70.7 & 92.4 & 0.000 & 80.0 & 90.5 & 0.041 & 64.3 & 98.2 & 0.000 \\
\hline 4.6 & 12.0 & 85.9 & 0.000 & 27.4 & 89.5 & 0.000 & 20.5 & 91.1 & 0.000 \\
\hline 4.7 & 25.0 & 43.5 & 0.000 & 36.8 & 55.8 & 0.000 & 24.1 & 58.9 & 0.000 \\
\hline 4.8 & 70.7 & 93.5 & 0.000 & 70.5 & 98.9 & 0.000 & 59.8 & 98.2 & 0.000 \\
\hline 4.9 & 62.0 & 69.6 & 0.618 & 57.9 & 80.0 & 0.046 & 38.4 & 75.0 & 0.000 \\
\hline 4.10 & 82.6 & 95.7 & 0.005 & 91.6 & 100 & 0.004 & 84.8 & 94.6 & 0.016 \\
\hline
\end{tabular}

$\mathrm{Q}_{1}=$ Before the questionnaire; $\mathrm{Q}_{2}=$ After the questionnaire.

workers are new and unexperienced, they will occupy a subordinate position. Consequently, they need to prove themselves as mature and capable workers. Furthermore, in their understanding, they have little impact on the reduction of their own risk. These statements can be applied to students that are close to entering the labour market.

Our results also confirm that students had limited knowledge on safety matters. Even though they already possessed some knowledge on topics such as PPE, accident consequences and qualifications of the maintenance staff, in general they had little knowledge on other topics, mainly the ones related to electricity, explosive atmospheres and fire protection. This combination between lack of information and pressure linked to be a newly-hired worker may lead young people to take risks that jeopardize their safety (Raykov and Taylor, 2013). On the other hand, tendency for high safety commitment levels before the OSP was observed. These results are interesting, since safety commitment is often linked to higher levels of companies' safety performance (Rodrigues et al., 2015a,b).

Better results pre-OSP regarding risk acceptance, safety commitment and intended safety behaviors were found among secondary school students, compared to vocational school students, probably be- 

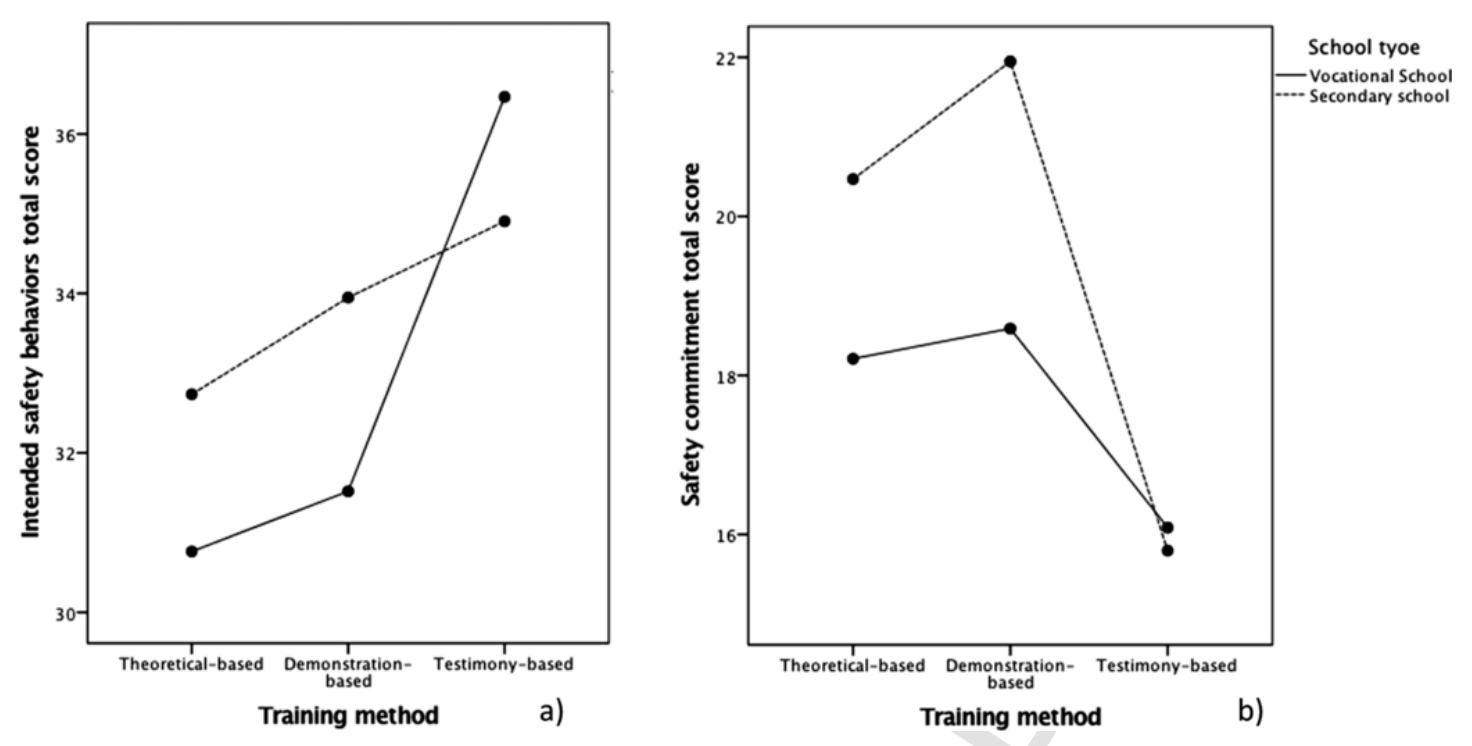

Fig. 1. Estimated marginal means by training method and school type: (a) Intended safety behaviors; (b) Safety commitment.

cause they are less willing to accept some risk scenarios or to see themselves adopting some unsafe behaviors. They can also have a tendency to see themselves getting deeply involved in safety matters. On the other hand, vocational school students probably have already seen some of these scenarios during their practical lessons, considering some of them more predictable. In regard to safety knowledge, better results were found for vocational school students. These students have practical lessons in simulated environments, as well as a certain amount of training hours in a working context, where some safety concepts should already be applied. Furthermore, in this group, almost $40 \%$ of students reported having received previous safety training. After the OSP, differences between schools disappear for risk acceptance and knowledge.

In general, results after the OSP confirm the findings of previous literature, showing its positive effect on some safety performance determinants (Linker et al., 2005; Liao, 2014; Twisk et al., 2014). Overall, and regardless of the training method adopted, students presented lower risk acceptance levels, a higher trend for safety behaviors, a higher level of safety commitment and significantly increased safety knowledge after the OSP. In what regards to safety behaviors, it is important to note that the study only analyzed the students' intentions; it cannot be assumed that this will translate into safer behaviors (Pisaniello et al., 2013).

Another important finding of this study was the trend for a stronger effect of more engaging methods on risk acceptance and intended safety behaviors. Overall, we found higher mean scores for the different items after the OSP in the groups submitted to the testimonies-based method, followed by the groups where the demonstration-based method was applied. However, a significant effect was found only for the testimonies-based method. Even though the three training methods applied in this study can be classified as low engaging (Robson et al., 2010), differences in the participation of students and in the approach to real contexts allowed us to indicate that the testimonies-based and demonstration-based methods are definitely more engaging than the theoretical-based method. Whenever the demonstration and testimonies-based methods were applied, dialogue and reflection were being promoted through analyses and discussions of the presented cases. Burke et al. (2007) stated that, in order to enhance learning, it is important to create conditions that promote dialogue and reflective thinking. Likewise, Linker et al. (2005) emphasized the use of scenarios, realistic photographs and other background material, to increase the en- gagement of students. The better results found for the testimonies-based method can be related to the use of real cases (Shearn, 2006; Pisaniello et al., 2013). Testimonies referred real cases of working accidents with which students could identify. Both the accident scenario and ways to avoid this kind of event in the future were presented and discussed. According to Pisaniello et al. (2013), this kind of method has the potential to raise awareness on the consequences of unsafe behavior, and, thereby, potentially change intended behaviors and their risk acceptance level. It is important to highlight that the testimonies were not meant to generate fear among students, but only to introduce them to some real cases. Fear-evoking strategies should be used with caution and were not found to be more effective than cognitive programmes (see e.g. Twisk et al., 2014).

When analyzing the differences between the three training methods for safety knowledge and safety commitment, results showed that the demonstration and theoretical-based produced significantly better results. In this case, factual information, frequently referred to as declarative, was found to be important in a way that it improves students' knowledge and safety commitment. Burke et al. (2007) have already emphasized the importance of this kind of training for all types of work, defending that it should focus on PPE, engaging in risk-reducing work practices, sharing health and safety information, and exercising employee's rights and responsibilities. The use of videos and images to demonstrate real work situations is also a good way to improve these two dimensions. Pisaniello et al. (2013) also reported that the use of videos resulted in more knowledge acquisition by students.

Despite the significance of these results, there were limitations. It should be recognized that the anonymity imposed by the schools was an important limitation. Questionnaires before and after the OSP could not be linked for statistical analysis; and, data were treated independently. Additionally, age and gender may have affected the observed differences between school types. However, due to the sample used in this study, where most of vocational students were males and the majority of secondary school students were females, and considering the age differences between groups, this analysis was not performed. Finally, it is important to note that the sessions were controlled for the trainer, who was always the same, as well as for the duration and school. However, factors such as the group size and the students' background might have had an important effect on the effectiveness of the training. 


\section{Conclusions}

This study contributes to the existing body of literature on the effectiveness of educational programmes about occupational risks. The results highlighted the importance of an OSP in reducing risk acceptance level of students and improving intended safety behaviors, safety commitment and students' knowledge about safety matters. Comparisons among intervention methods suggest that more engaging methods, such as the testimonies-based one, have a stronger effect on students' risk acceptance and intended safety behaviors; however, the expositive and demonstrative methods are more suitable in equipping students with essential knowledge and improve their commitment to safety issues. According to these findings, the training methods used in an OSP should be adjusted to the purpose of the intervention. Mixed methods may be a good solution to improve the effectiveness of the intervention in different dimensions.

\section{References}

Apostolico, A.A., Shendell, D.G., 2016. Injury surveillance and associations with socioeconomic status indicators among youth/young workers in New Jersey secondary schools. Environ. Health 15-22.

Aronsson, G., Gustafsson, K., Dallner, M., 2002. Work environment and health in different types of temporary jobs. Eur. J. Work Organ. Psych. 11 (2), 151-175.

Balanay, J.A., Adesina, A., Kearney, G.D., Richards, S.L., 2014. Assessment of occupational health and safety hazard exposures Among working college students. Am. J. Ind. Med. $57,114-124$

Breslin, F.C., Smith, P., 2005. Age-related differences in work injuries: a multivariate, population-based study. Am. J. Ind. Med. 8, 50-56.

Breslin, F.C., Day, D., Tompa, E., Irvin, E., Bhattacharyya, S., Clarke, J., Wang, A., 2007. Non agricultural work injuries among youth. A systematic review. Am. J. Prev. Med. 21 (2), 151-162.

Breslin, F.C., Polzer, J., MacEachen, E., Morrongiello, B., Shannon, H., 2007. Workplace injury or "part of the job"?: Towards a gendered understanding of injuries and complaints among young workers. Soc. Sci. Med. 64, 782-793.

Burke, M.J., Sarpy, S.A., Smith-Crowe, K., Chan-Serafin, S., Salvador, R.O., Islam, G., 2006. Relative effectiveness of worker safety and health training methods. Am. J. Publ. Health 96 (2), 315-324.

Burke, M.J., Scheurer, M.L., Meredith, R.J., 2007. A dialogical approach to skill development: the case of safety and health skills. Human Resour. Manage. Rev. 17, 235-250.

Delp, L., Runyan, C.W., Brown, M., Bowling, J.M., Jahan, S., 2002. Role of work permits in teen workers' experiences. Am. J. Ind. Med. 41, 477-482.

Eurostat, 2009. Statistics Main Tables: Accidents at Work-Incidence Rate. European Commission.

Field, A., 2009. Discovering Statistics Using SPSS, second ed. Sage, Los Angeles.

Goldenhar, L.M., Moran, S.K., Colligan, M., 2001. Health and safety training in a sample of open-shop construction companies. J. Saf. Res. 32 (2), 237-252.

Hair, J., Black, B., Anderson, R., Tatham, R., 1995. Multivariate Data Analysis: Text and Readings, fourth ed. Prentice Hall, Upper Saddle River, NJ, USA.

Harms-Ringdahl, L., 2001. Safety Analysis: Principles and Practice in Occupational Safety, second ed. CRC PRESS, USA.

International Labour Organisation (ILO), 2012. Decent Work Indicators - Concepts and Definitions. International Labour Organisation.
Laberge, M., Calvet, B., Fredette, M., Tabet, N., Tondoux, A., Bayard, D., Breslin, C., 2016. Unexpected events: learning opportunities or injury risks for apprentices in low-skilled jobs? A pilot study. Saf. Sci. 86, 1-9.

Lavack, A.M., Magnuson, S.L., Deshpande, S., Basil, D.Z., Basil, M.D., Mintz, J.H., 2008. Enhancing occupational health and safety in young workers: the role of social marketing. Int. J. Nonprofit Volunt. Sec. Mark. 13 (3), 193-204.

Liao, M.-Y., 2014. An evaluation of an airline cabin safety education program for elementary school children. Eval. Program Plan. 43, 27-37.

Linker, D., Miller, M.E., Freeman, K.S., Burbacher, T., 2005. Health and safety awareness for working teens: developing a successful, statewide program for educating teen workers. Family Commun. Health 28 (3), 225-238.

NIOSH, 2015. Youth@Work-Talking Safety: A Safety and Health Curriculum for Young Workers. DHHS (NIOSH) Publication No. 2015-173. Department of Health and Human Services, Centers for Disease Control and Prevention, National Institute for Occupational Safety and Health, California.

Nunnally, J.C., Bernstein, I.H., 1994. Psychometric Theory. McGraw-Hill, New York.

OECD, 2014. Education policy outlook. Retrieved from < Organisation for Economic Co-operation and Development (OECD), Portugal, $>$.

Ontario Ministry of Labour, 2012. Health \& Safety at Work - Prevention Starts Here Worker Health and Safety Awareness in 4 Steps. Queen's Printer of Ontario, Ontario.

Pisaniello, D.L., Stewart, S.K., Jahan, N., Pisaniello, S.L., Winefield, H., Braunack-Mayer, A., 2013. The role of high schools in introductory occupational safety education teacher perspectives on effectiveness. Saf. Sci. 55, 53-61.

Quinlan, M., Mayhew, C., Bohle, P., 2001. The global expansion of precarious employment, work disorganization, and consequences for occupational health: a review of recent research. Int. J. Health Serv. 31, 335-414.

Raykov, M., Taylor, A., 2013. Health and safety for Canadian youth in trades. Just Labour: Can. J. Work Soc. 20, 33-49.

Robson, L., Stephenson, C., Schulte, P., Amick, B., Chan, S., Bielecky, A., Wang, A., Heidotting, T., Irvin, E., Eggerth, D., Peters, R., Clarke, J., Cullen, K., Boldt, L., Rotunda, C., Grubb, P., 2010. A Systematic Review of the Effectiveness of Training \& Education for the Protection of Workers. Institute for Work \& Health, Toronto.

Rodrigues, M.A., Arezes, P., Leão, C.P., 2015. Safety climate and its relationship with furniture companies' safety performance and workers' risk acceptance. Theor. Issues Ergon. Sci. 16 (4), 412-428.

Rodrigues, M.A., Arezes, P., Leão, C.P., 2015. Multilevel model of safety climate for furniture industries. Work: J. Prevent., Assess. Rehab. 51 (3), 557-570.

Runyan, C., Schulman, M., Dal Santo, J., Bowling, J., Agans, R., Ta, M., 2007. Work-related hazards and workplace safety of us adolescents employed in the retail and service sectors. Pediatrics 119 (3), 526-534.

Schulte, P.A., Stephenson, C.M., Okun, A.H., Palassis, J., Biddle, E., 2005. Integrating oc cupational safety and health information into vocational and technical education and other workforce preparation programs. Am. J. Pub. Health 95 (3), 404-411.

Shearn, P., 2006. Teaching practice in safety education: qualitative evidence. Res. Pap. Educ. 21, 335-359.

Smith, P., Mustard, C., 2007. How many employees receive safety training during their first year of a new job?. Injury Prevent. 13, 37-41

Thamrin, Y., Pisaniello, D., Stewart, S., 2010. Time trends and predictive factors for safety perceptions among incoming South Australian university students. J. Saf. Res. 41 (1), $59-63$.

Turnberg, W., Daniell, W., 2008. Evaluation of a healthcare safety climate measurement tool. J. Saf. Res. 39 (6), 563-568.

Twisk, D.A.M., Vlakveld, W.P., Commandeur, J.J.F., Shope, J.T., Kok, G., 2014. Five road safety education programmes for young adolescent pedestrians and cyclists: a multi-programme evaluation in a field setting. Accid. Anal. Prev. 66, 55-61.

Webster, J., 2013. Young workers [Internet]. European Agency for Safety and Health at Work (EU-OSHA). Retrieved from < https://osha.europa.eu/en/themes/ young-workers $>$.

Zierold, K.M., Anderson, H.A., 2006. Severe injury and the need for improved safety training among working teens. Am. J. Health Behav. 30 (5), 525-532. 